\title{
Serum 14-3-3 $\eta$ is a Novel Marker that Complements Current Serological Measurements to Enhance Detection of Patients with Rheumatoid Arthritis
}

\author{
Walter P. Maksymowych, Stanley J. Naides, Vivian Bykerk, Katherine A. Siminovitch, \\ Dirkjan van Schaardenburg, Maarten Boers, Robert Landewé, Désirée van der Heijde, \\ Paul-P. Tak, Mark C. Genovese, Michael E. Weinblatt, Edward C. Keystone, Olga S. Zhukov, \\ Rania W. Abolhosn, Joanna M. Popov, Karin Britsemmer, Arno W. van Kuijk, \\ and Anthony Marotta
}

\begin{abstract}
Objective. Serum 14-3-3 $\eta$ is a novel joint-derived proinflammatory mediator implicated in the pathogenesis of rheumatoid arthritis (RA). In our study, we assessed the diagnostic utility of 14-3-3 $\eta$ and its association with standard clinical and serological measures.

Methods. A quantitative ELISA was used to assess $14-3-3 \eta$ levels. Early $(n=99)$ and established patients with RA $(n=135)$ were compared to all controls $(n=385)$, including healthy subjects $(n=$ 189). The sensitivity, specificity, positive and negative predictive values of $14-3-3 \eta$, and the likelihood ratios (LR) for RA were determined through receiver-operator curve analysis. The incremental value of adding 14-3-3 $\eta$ to anticitrullinated protein antibody (ACPA) and rheumatoid factor (RF) in diagnosing early and established RA was assessed.

Results. Serum 14-3-3ך differentiated established patients with RA from healthy individuals and all controls ( $\mathrm{p}<0.0001$ ). A serum $14-3-3 \eta$ cutoff of $\geq 0.19 \mathrm{ng} / \mathrm{ml}$ delivered a sensitivity and specificity of $77 \%$ and $93 \%$, respectively, with corresponding LR positivity of 10.4 . At this cutoff in early RA, $64 \%$ of patients with early RA were positive for $14-3-3 \eta$, with a corresponding specificity of $93 \%$ (LR+ of 8.6), while 59\% and 57\% were positive for ACPA or RF, respectively. When ACPA, RF, and 14-3-3 $\eta$ positivity were used in combination, 77 of the 99 patients (78\%) with early RA were positive for any 1 of the 3 markers. Serum $14-3-3 \eta$ did not correlate with C-reactive protein,

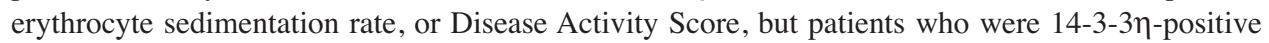
had significantly worse disease.

Conclusion. Serum 14-3-3 $\eta$ is a novel RA mechanistic marker that is highly specific, associated with worse disease, and complements current markers, enabling a more accurate diagnosis of RA. (First Release Aug 15 2014; J Rheumatol 2014;41:2104-13; doi:10.3899/jrheum.131446)
\end{abstract}

Key Indexing Terms:

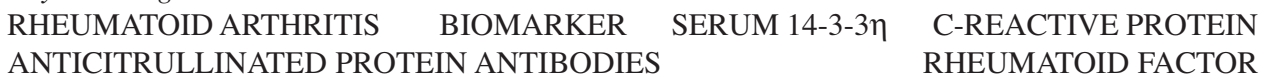

From the University of Alberta, Edmonton, Alberta; Augurex Life Sciences Corp., North Vancouver, British Columbia; Mount Sinai Hospital, Toronto, Ontario, Canada; Quest Diagnostics Nichols Institute, San Juan Capistrano; Stanford University Medical Center, Palo Alto, California; Hospital for Special Surgery, New York, New York; Brigham and Women's Hospital, Boston, Massachusetts, USA; Vrije Universiteit University Medical Center; Academic Medical Center/University of Amsterdam; Jan van Breemen Research Institute, Reade organization, Amsterdam; the Department of Rheumatology, Leiden University Medical Center, Leiden, the Netherlands; University of Cambridge, Cambridge; GlaxoSmithKline, Stevenage, $U K$.

Supported by Augurex Life Sciences Corp., North Vancouver, British Columbia, Canada.

W.P. Maksymowych, MD, Professor of Medicine, University of Alberta; S.J. Naides, MD, Quest Diagnostics Nichols Institute; V. Bykerk, MD, Hospital for Special Surgery; K.A. Siminovitch, MD, Mount Sinai Hospital; D. van Schaardenburg, MD, Jan van Breemen Research Institute; M. Boers, MD, Vrije Universiteit University Medical Center;
R. Landewé, MD, Academic Medical Center/University of Amsterdam, D. van der Heijde, MD, Department of Rheumatology, Leiden University Medical Center; P-P. Tak, MD, Academic Medical Center/University of Amsterdam, University of Cambridge, GlaxoSmithKline; M.C. Genovese, MD, Stanford University Medical Center; M.E. Weinblatt, MD, Brigham and Women's Hospital; E.C. Keystone, MD, Mount Sinai Hospital; O.S. Zhukov, MS; R.W. Abolhosn, BS; J.M. Popov, MD, PhD, Quest Diagnostics Nichols Institute; K. Britsemmer, $M D$, Jan van Breemen Research Institute; A.W. van Kuijk, MD, Academic Medical Center/University of Amsterdam; A. Marotta, PhD, Augurex Life Sciences Corp.
Address correspondence to Dr. W.P. Maksymowych, Professor of Medicine, University of Alberta, 562 Heritage Medical Research Building, Edmonton, Alberta T6G 2S2, Canada.
E-mail: walter.maksymowych@ualberta.ca
Full Release Article. For details see Reprints/Permissions at jrheum.org Accepted for publication June 10, 2014. 
Rheumatoid arthritis (RA) is a chronic autoimmune disease that affects about $1.5 \%$ of the population. It is driven by multiple pathophysiological factors and manifests with high heterogeneity both among and within patients along the disease course. If left untreated, RA results in severe joint destruction leading to impaired physical function and workplace disability $1,2,3,4$.

Supporting the concept of a "window of opportunity" for therapeutic intervention, several studies have reported on the benefits of initiating disease-modifying antirheumatic drug (DMARD) therapy within the first 12 weeks following symptom onset. It is now widely accepted that identification of RA in its earliest stages, assessment of disease severity at diagnosis, and implementation of an effective treatment strategy can significantly improve a patient's prognosis ${ }^{5}$. In recognition of this, new RA classification criteria were established in 2010 that focus on defining the disease by its earlier features ${ }^{6}$. Classification of RA according to these new criteria relies on the evaluation of joint involvement, measurement of acute-phase reactants and serological markers, and assessment of symptom duration. For serological measurements, higher weighting is ascribed to patients who have higher titers of both anticitrullinated protein antibodies (ACPA) and rheumatoid factor (RF) compared to those with low levels or who are seronegative. Seronegativity in both early and established RA remains a major limitation of these 2 markers highlighting the need for new complementary markers that will improve diagnostic sensitivity ${ }^{7,8}$. New markers are also needed to better stratify patients into different risk categories because current markers only account for $32 \%$ of the total variance in predicting joint destruction ${ }^{9}$.

In RA, certain markers may be present as a consequence of the disease as "bystanders" and others may be more intimately linked to the disease pathogenesis. In 2007, Kilani, et al demonstrated by Western blot analysis that a novel soluble biomarker, 14-3-3 $\eta$, was present at significantly higher levels in the synovial fluid and serum of patients with arthritis compared to healthy individuals and that serum levels correlated strongly with the matrix metalloproteinases (MMP) MMP-1 and MMP- $3^{10}$.

There are 7 isoforms of the 14-3-3 family of intracellular chaperone proteins $(\alpha / \beta, \gamma, \delta / \zeta, \varepsilon, \eta, \theta / \tau, \sigma)$. These highly conserved proteins are acidic at physiologic $\mathrm{pH}$, possess a molecular weight of about $28 \mathrm{kDa}$, and share more than $50 \%$ amino acid homology between isoforms. Structurally, they have $9 \alpha$ helices with variable amino- and carboxyl-termini. Through their N-terminus, the 14-3-3 proteins either homo- or hetero-dimerize, forming a cup-like structure known as the amphipathic groove. Through this groove, 14-3-3 proteins interact with more than 200 intracellular proteins, thereby regulating an array of biological processes including protein synthesis, cellular metabolism, protein trafficking, signal transduction, and cytoskeletal transport ${ }^{10}$.
Of the isoforms, only 14-3-3 $\eta$ was present in synovial fluid with levels of at least 5-fold higher than those found in matched sera, implicating the joint as the likely source of 14-3-3 $\eta$. Externalization of $14-3-3 \eta$ is believed to be mediated in part through exosomes because this family of proteins has been described as a key component of these microvesicles ${ }^{11,12}$. In the extracellular environment, at concentrations present in the serum of patients with RA, soluble $14-3-3 \eta$ possesses ligand activity, preferentially activating cells of the innate immune system ${ }^{10}$. Soluble 14-3-3 $\eta$ acts through signaling cascades such as the extracellular signal-regulated kinase and p38 pathway to upregulate proinflammatory cytokines, including interleukin $1 \beta$ (IL-1 $1 \beta$ ), IL-6, tumor necrosis factor- $\alpha$ (TNF- $\alpha$ ), and factors that are involved in joint degradation such as MMP-9 and receptor activator of nuclear factor- $\mathrm{\kappa B}$ ligand (RANKL) ${ }^{13}$.

In our study, we assessed the discriminative power of serum 14-3-3 $\eta$ for established RA using healthy subjects and disease controls to determine the sensitivity and speci-

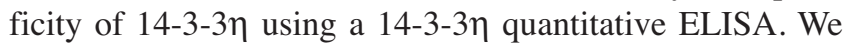
also assessed to what degree it enhanced diagnostic utility when combined with standard clinical and serological variables in early RA.

\section{MATERIALS AND METHODS}

Patients with RA and controls. Demographics for all participants, as well as clinical characteristics of the early and established cohorts with RA, are provided in Table 1. Serum 14-3-3 $\eta$ levels were measured in banked samples (stored at $-80^{\circ} \mathrm{C}$ ) from 135 established patients with RA classified according to the American College of Rheumatology (ACR) 1987 criteria ${ }^{14}$. Patients with established RA were from the Rheumatoid Arthritis Pharmacovigilance Program of Outcomes Research Team cohort from the University of Alberta, Canada $(\mathrm{n}=75)$, and from Bioreclamation Inc. $(\mathrm{n}=$ 60 ). These patients were taking standard DMARD, but naive to biological

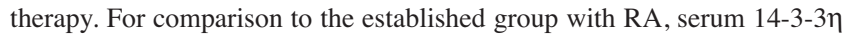
levels were analyzed from a total of 385 controls: 189 presumed healthy subjects (from Quest Diagnostics and BioChemed LLC), 72 patients with arthritis without RA (patients with ankylosing spondylitis from the University of Alberta, classified according to the modified New York Criteria, $n=67$; gout, $n=5$ ), 25 patients with connective tissue disorders (patients with systemic lupus erythematosus, $\mathrm{n}=10$; systemic sclerosis, $\mathrm{n}$ $=5$; Sjögren syndrome, $\mathrm{n}=5$; and osteoporosis, $\mathrm{n}=5$ ), 45 patients with various inflammatory diseases (patients with Crohn disease, $\mathrm{n}=10$; ulcerative colitis, $\mathrm{n}=10$; psoriasis, $\mathrm{n}=10$; type 1 diabetes, $\mathrm{n}=10$; and multiple sclerosis, $\mathrm{n}=5$ ), 24 with psoriatic arthritis (PsA; from the Academic Medical Center, Netherlands, 12 of whom had visible signs of joint damage as determined through radiographic adjudication), and 30 patients with osteoarthritis (OA; Mount Sinai Hospital, Canada). Diagnoses of disease controls were confirmed by the attending physician.

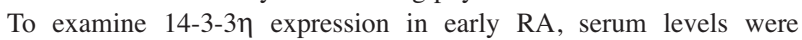
measured in 99 patients who were naive of DMARD therapy and had a median disease duration of 3.4 months. Patients with early RA were from the Toronto Early Arthritis Cohort (TEACH; Mount Sinai Hospital, Canada, $\mathrm{n}=25$ ), the Intensified-Combination Therapy with Rheumatoid Arthritis cohort (iCOBRA; Vrije Universiteit University Medical Center, the Netherlands, $n=12$ ), and the Reade prospective cohort with early RA (Reade, the Netherlands, $\mathrm{n}=62$ ). The median [(with interquartile range (IQR)] and mean (SD), respectively, disease duration for the cohorts with early RA were TEACH -1.0 months (0.0-3.7) and 7.8 (42.4) months; COBRA -1.0 months (1.0-2.0) and 1.4 (1.1) months; and Reade 4.2

Personal non-commercial use only. The Journal of Rheumatology Copyright @ 2014 . All rights reserved. 
Table 1A. Populations assessed and patient demographics.

\begin{tabular}{|c|c|c|c|c|c|c|c|}
\hline Group, $\mathrm{n}$ & $\begin{array}{l}\text { Age, yrs, } \\
\text { Mean (SD) }\end{array}$ & $\begin{array}{c}\text { Sex } \\
(\% \text { female })\end{array}$ & $\begin{array}{l}\text { 14-3-3ך, ng/ml, } \\
\text { Median (IQR) }\end{array}$ & $\begin{array}{l}\text { ACPA, U/ml, } \\
\text { Median }(\mathrm{IQR})^{\mathrm{n}}\end{array}$ & $\mathrm{ACPA}+{ }^{\mathrm{n}}$ & $\begin{array}{c}\mathrm{RF}, \mathrm{IU} / \mathrm{ml}, \\
{\text { Median }(\mathrm{IQR})^{\mathrm{n}}}^{\text {nof }}\end{array}$ & $\mathrm{RF}+{ }^{\mathrm{n}}$ \\
\hline Early RA, 99 & $53(13)$ & $78(79)$ & $0.76(0.03-5.61)$ & $77.0(5.0-1028.0)^{98}$ & $58(59 \%)^{98}$ & $53.0(10.0-180.5)$ & $57(58 \%)$ \\
\hline Controls, 385 & $46(15)$ & $204(53)$ & $0.02(0.02-0.09)$ & $16.0(16.0-16.0)^{383}$ & $6(2 \%)^{383}$ & $5.0(5.0-5.0)^{383}$ & $61(16 \%)^{383}$ \\
\hline Healthy, 189 & $45(17)$ & $107(57)$ & $0.00(0.00-0.06)$ & $16.0(16.0-16.0)$ & $1(0.5 \%)$ & $5.0(5.0-5.0)$ & $29(15 \%)$ \\
\hline Arthro, 72 & $43(13)$ & $18(25)$ & $0.02(0.00-0.09)$ & $16.0(16.0-16.0)^{70}$ & $0(0 \%)^{70}$ & $5.0(5.0-5.0)^{70}$ & $8(11 \%)^{70}$ \\
\hline PsA, 24 & $45(13)$ & $9(38)$ & $0.00(0.00-0.82)$ & $16.0(16.0-16.0)$ & $1(4 \%)$ & $5.0(5.0-5.0)$ & $5(21 \%)$ \\
\hline $\mathrm{OA}, 30$ & $56(7.5)$ & $21(70)$ & $0.00(0.00-0.00)$ & $16.0(16.0-16.0)$ & $2(7 \%)$ & $5.0(5.0-5.0)$ & $5(17 \%)$ \\
\hline
\end{tabular}

IQR: interquartile range; ACPA: anticitrullinated protein antibodies; RF: rheumatoid factor; RA: rheumatoid arthritis; Est RA: established RA; Arthro: arthropathies (ankylosing spondylitis $=67$, gout $=5$ ); CTD: connective tissue disorders (systemic lupus erythematosus $\mathrm{n}=10$, systemic sclerosis $\mathrm{n}=5$, Sjögren syndrome $n=5$, and osteoporosis $n=5$ ); ID: inflammatory diseases (Crohn disease $n=10$, ulcerative colitis $n=10$, psoriasis $n=10$, type 1 diabetes $\mathrm{n}=10$, and multiple sclerosis $\mathrm{n}=5$ ); PsA: psoriatic arthritis; OA: osteoarthritis.

Table 1B. Clinical characteristics of established and early RA cohorts.

\begin{tabular}{|c|c|c|}
\hline Measure & $\begin{array}{c}\text { Established RA, } \mathrm{n}=135, \\
\text { Median }(\mathrm{IQR})^{\mathrm{n}}\end{array}$ & $\begin{array}{l}\text { Early RA, } \mathrm{n}=99, \\
{\text { Median }(\mathrm{IQR})^{\mathrm{n}}}\end{array}$ \\
\hline Disease duration & $11.5 \mathrm{yrs}(6.0-18.8)^{60}$ & $3.4 \operatorname{mos}(1.6-5.8)^{99}$ \\
\hline DAS28 & $6.8(5.9-7.4)^{75}$ & $5.5(4.6-6.5)^{99}$ \\
\hline HAQ & $2.0(1.5-2.4)^{75}$ & $1.3(0.7-1.6)^{36}$ \\
\hline $\mathrm{ESR}, \mathrm{mm} / \mathrm{h}$ & $42.0(25.0-47.0)^{75}$ & $27.0(15.6-45.0)^{98}$ \\
\hline $\mathrm{CRP}, \mathrm{mg} / \mathrm{l}$ & $18.9(7.4-48.7)^{74}$ & $14.0(4.3-31.5)^{97}$ \\
\hline $\mathrm{RF}, \mathrm{IU} / \mathrm{ml}$ & $100(25-100)^{133}$ & $53.0(10.0-180.5)^{74}$ \\
\hline ACPA, $\mathrm{U} / \mathrm{ml}$ & $250(66.5-250)^{125}$ & $77.0(5.0-1028)^{98}$ \\
\hline $14-3-3 \eta, \mathrm{ng} / \mathrm{ml}$ & $1.12(0.23-5.23)^{135}$ & $0.76(0.03-5.61)^{99}$ \\
\hline
\end{tabular}

$\mathrm{n}$ : Superscripted numbers refer to numbers of patients. RA: rheumatoid arthritis; IQR: interquartile range; DAS28: Disease Activity Score, 28-joint count; HAQ: Health Assessment Questionnaire; ESR: erythrocyte sedimentation rate; CRP: C-reactive protein; RF: rheumatoid factor; ACPA: anticitrullinated protein antibodies.

months (2.9-3.7) and 6.8 (6.7) months. Serum 14-3-3ך levels of patients with early RA were compared to patients with OA $(n=30$, from Mount Sinai Hospital, Canada) because the differential diagnosis between OA and early RA is often difficult for primary practitioners. Serum 14-3-3ך levels were also compared to healthy individuals and all controls.

Our study was performed in accordance with the Helsinki Declaration. Written informed consent was obtained from all study participants and ethics approval was obtained from the Health Research Ethics Board of the University of Alberta, the Ethical Review Board of Vrije Universiteit University of Amsterdam Medical Center, the Jan van Breemen Institute, the Mount Sinai Health Ethics Review Board of the University of Toronto, and the Western Institutional Review Board for the Quest Diagnostics Nichols Institute.

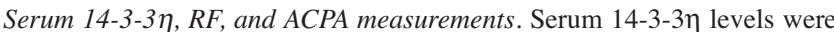
measured using the quantitative 14-3-3 $\eta$ ELISA (Augurex Life Sciences Corp.), with the exception of 134 healthy subjects whose levels were measured using the laboratory-developed test at the Quest Diagnostics Nichols Institute. The 2 assays use comparable clinical cutoffs for positivity $(0.19 \mathrm{vs} 0.20 \mathrm{ng} / \mathrm{ml})$, and substantial equivalence testing demonstrated that the $14-3-3 \eta$ values on the 2 different assays were within $15 \%$ of each other $(\mathrm{r}=0.94, \mathrm{p}<0.0001)$

The development, validation, and calibration of the commercially available quantitative 14-3-3 $\eta$ ELISA (Augurex assay) is extensively detailed in the appended supplement (supplementary data available online at jrheum.org), as is the concordance between the Augurex assay and the laboratory-developed test (Quest Diagnostics). Both assays use the same monoclonal antibodies in a 2-sided, sandwich ELISA, and the same calibrator was used to generate the standard curve. Briefly, in the Augurex assay, serum samples were diluted 1:20 using the supplied assay dilution buffer. One hundred $\mu 1$ of either the corresponding calibrator or sample were incubated in a 96-well plate shaker for $2 \mathrm{~h}$ at $50 \mathrm{rpm}$ and $27^{\circ} \mathrm{C}$. Following incubation, the plates were washed 4 consecutive times with wash buffer, and then incubated with the prediluted horseradish peroxidaseconjugate antibody for $1 \mathrm{~h}$ at room temperature without shaking. The plates were washed 4 additional times and subsequently incubated with $3,3^{\prime}$, 5,5'-tetramethylbenzidine substrate for $30 \mathrm{~min}$, at which time the reaction was terminated through the addition of $1 \mathrm{~N}$ hydrochloric acid stop solution

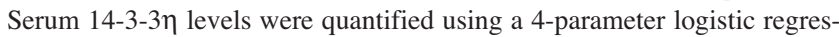
sion curve generated against the diluted calibrators. The accuracy of the results was evaluated by examining the precision of the back-calculated concentrations of each of the calibrators and the corresponding measurements of 3 quality control samples with 14-3-3ך levels within the linear range of the assay. All clinical samples were run in duplicate. Samples with levels below the reportable range were assigned a concentration of $0 \mathrm{ng} / \mathrm{ml}$,

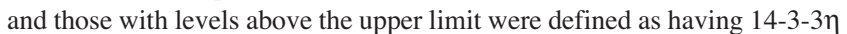
levels $>20 \mathrm{ng} / \mathrm{ml}$.

$\mathrm{RF}$ and ACPA assays were performed as per manufacturers' protocols (RF: Quanta Lite RF IgG ELISA, RF Quanta Lite RF IgA ELISA, RF Quanta Lite RF IgM ELISA; ACPA: RF Quanta Lite CCP3 IgG ELISA). The assay calibrators were run in duplicates with patient samples singly.

Statistical methods. Descriptive statistics were used to express clinical and serological measurements according to disease category and healthy controls. Median 14-3-3 $\eta$ serum expression differences between the RA and control groups were tested for statistically significant differences using a 2-tailed Mann-Whitney U test. To compare more than 2 groups, the Kruskal-Wallis test with the posthoc Dunn's Multiple Comparison method was used to determine whether statistical significance existed across the groups. If a statistical difference was observed, the significance between the 2 groups was determined using the Mann-Whitney $U$ test. Receiver-operating characteristic (ROC) curves were used to evaluate the diagnostic utility of $14-3-3 \eta$ as estimated by the area under the curve

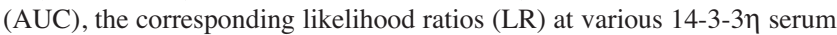
concentration cutoffs, and the corresponding positive and negative predictive values (PPV; NPV). The additional diagnostic value added by

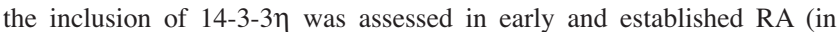
addition to RF or ACPA alone and together). An incremental benefit/change was calculated as follows:

$$
[(\mathrm{A}-\mathrm{B}) \div \mathrm{B}] \times 100
$$


Further, sensitivity and specificity of RF, ACPA, and RF and/or ACPA with and without inclusion of 14-3-3 $\eta$ was calculated for both the groups with early and established RA with reference to the healthy controls and all controls (healthy plus disease controls). Because $14-3-3 \eta$ has been described as a mechanistic marker that participates in the perpetuation of inflammation and joint damage based on its in vitro cell stimulatory effects,

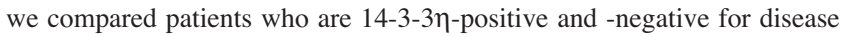
activity and status using the Mann-Whitney $U$ test. The relationship between $14-3-3 \eta$ and other serological markers was assessed using the Spearman's rank correlation coefficient procedure for non-normally distributed data and Pearson's product-moment correlation for normally distributed variables. Distribution normality was established by the Shapiro-Wilk normality test.

All statistical analyses were completed with Prism 6 (GraphPad Software Inc.) or JMP10 (SAS Institute Inc.). An $\alpha$ of $p<0.05$ denoted statistical significance.

\section{RESULTS}

Specificity of 14-3-3 $\eta$ for established RA. Median (IQR) serum $14-3-3 \eta$ concentrations $(\mathrm{ng} / \mathrm{ml})$ were significantly higher $(\mathrm{p}<0.0001)$ in patients with established RA $[1.12$ $\mathrm{ng} / \mathrm{ml}(0.22-6.87)]$ as compared to healthy individuals $[0.00$ $\mathrm{ng} / \mathrm{ml}(0.00-0.06)]$ and all controls $[0.02 \mathrm{ng} / \mathrm{ml}(0.00-0.09)$; Figure 1A]. ROC curve analysis comparing established RA with healthy subjects demonstrated a significant ( $\mathrm{p}<$ $0.0001)$ AUC of 0.89 (95\% CI, 0.85-0.93; Figure 1B). At a cutoff of $\geq 0.19 \mathrm{ng} / \mathrm{ml}$, the ROC curve yielded a sensitivity of $77.0 \%$, a specificity of $92.6 \%$, an LR positivity of 10.4 , a PPV of 0.70 , and an NPV of 0.80 . When comparing established RA with all controls, the same cutoff yielded a sensitivity of $77.4 \%$ and specificity of $86.0 \%$. At cutoffs of $\geq 0.40$ $\mathrm{ng} / \mathrm{ml}$ and $\geq 0.80 \mathrm{ng} / \mathrm{ml}, 2$ serum $14-3-3 \eta$ concentrations below the observed group median in our established RA study population, the specificity increased to $90.4 \%$ and $94.0 \%$, and the corresponding sensitivities were $68.9 \%$ (LR $=7.2)$ and $55.6 \%(\mathrm{LR}=9.3)$.

Although levels in PsA were numerically higher than in other control groups (Figure 1A), the Kruskal-Wallis ANOVA across all of the control groups did not reveal any significant differences among any of the control groups tested. However, Dunn's posttest revealed that levels in erosive PsA were significantly different from those in patients with nonerosive PsA $(\mathrm{p}<0.05)$, but not when compared to patients with psoriasis alone. The

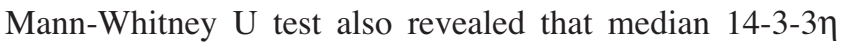
levels were significantly higher in patients with erosive PsA $(0.23 \mathrm{ng} / \mathrm{ml})$ than in the nonerosive group $(0.0 \mathrm{ng} / \mathrm{ml}, \mathrm{p}=$ 0.026). Figure $1 \mathrm{C}$ illustrates that $14-3-3 \eta$ levels were similar in patients with psoriasis and nonerosive PsA

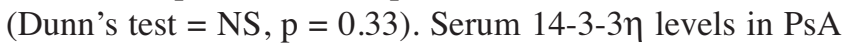
were significantly lower than in established $(\mathrm{p}<0.0001)$ and early RA ( $\mathrm{p}=0.0005)$.

Serum 14-3-3 7 expression in early $R A$. ANOVA $(\mathrm{p}=0.27)$ revealed that there were no significant differences in $14-3-3 \eta$ serum expression between the 3 early groups with RA (Reade, TEACH, and iCOBRA). Consequently, they were combined for further analyses. Median (IQR) serum 14-3-3 $\eta$ concentrations ( $\mathrm{ng} / \mathrm{ml}$ ) were significantly higher $(\mathrm{p}<0.0001)$ in patients with early RA $[0.76 \mathrm{ng} / \mathrm{ml}$ (0.03-5.61)] when compared to patients with OA (Table 1A). Median 14-3-3 $\eta$ levels in early RA were also significantly higher than in healthy individuals $(\mathrm{p}<0.0001)$ and all controls ( $p<0.0001)$. ROC curve analysis comparing early RA with healthy controls demonstrated a significant ( $\mathrm{p}<0.0001)$ AUC of 0.81 (95\% CI, 0.76-0.87; Figure 1D). At a cutoff of $\geq 0.19 \mathrm{ng} / \mathrm{ml}$, the ROC curve yielded a sensitivity of $63.6 \%$, a specificity of $92.6 \%$, an LR positivity of 8.6, a PPV of 0.57 , and an NPV of 0.78 . When comparing early RA with OA at the level of $\geq 0.19 \mathrm{ng} / \mathrm{ml}$, the sensitivity and specificity were $63.6 \%$ and $83.3 \%$, respectively, with an LR of 3.8. At cutoffs of $\geq 0.40 \mathrm{ng} / \mathrm{ml}$ and $\geq 0.80 \mathrm{ng} / \mathrm{ml}$, the specificity increased to $93.3 \%$ and $96.7 \%$, and the corresponding sensitivities were $59.6 \%(\mathrm{LR}=8.8)$ and $49.5 \%$ $(\mathrm{LR}=14.9)$. When comparing early RA with all controls at the $\geq 0.19 \mathrm{ng} / \mathrm{ml}$, the sensitivity and specificity were $63.6 \%$ and $86.0 \%$, respectively, with an LR of 4.5 . At cutoffs of $\geq$ $0.40 \mathrm{ng} / \mathrm{ml}$ and $\geq 0.80 \mathrm{ng} / \mathrm{ml}$, the specificity increased to $90.4 \%$ and $94.0 \%$, and the corresponding sensitivities were $59.6 \%(\mathrm{LR}=6.2)$ and $48.5 \%(\mathrm{LR}=8.1)$.

Relationship of serum 14-3-3 $\eta$ with clinical measures. The correlation matrices presented in Tables 2A and 2B illustrate the relationship between the levels of $14-3-3 \eta$ and clinical and serological variables in the cohorts with early and established RA, respectively. As expected, a significant correlation between ACPA and RF was observed in both cohorts. Similarly, serum 14-3-3 $\eta$ also correlated with the titers of ACPA and RF.

Because ACPA and RF are routinely used together to inform an RA diagnosis, the incremental benefit of adding 14-3-3 $\eta$ to each of the markers was assessed. As illustrated in Table 3A, of the 99 patients assessed with early RA, 58 $(59 \%), 56(57 \%)$, and $63(64 \%)$ were positive for ACPA, $\mathrm{RF}$, and $14-3-3 \eta$, respectively. As expected in a cohort with advanced RA, the proportion of patients with positivity in all 3 markers was greater in the cohort with established RA (ACPA 79\%, RF 85\%, and 14-3-3 77\%). When assessing the cohort with early RA, adding RF to ACPA increased diagnostic detection from $59 \%$ to $72 \%$. Adding $14-3-3 \eta$ to ACPA also resulted in an identification rate of $72 \%$. However, when combined with RF, 14-3-3 $\eta$ increased the diagnostic detection from $57 \%$ to $75 \%$. All 3 markers together identified $78 \%$ of this patient population with early

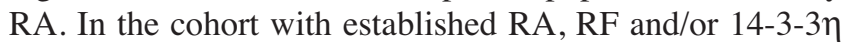
had a greater identification rate than ACPA and/or RF $(94 \%$ vs $88 \%$ ). When combining 14-3-3 $\eta$ with ACPA or when combining all 3 biomarkers together, the identification rate increased marginally to $96 \%$.

The sensitivity and specificity of RF, ACPA, and RF and/or ACPA with or without the inclusion of $14-3-3 \eta$ is presented in Table 3B. Regardless of the comparison, the

Personal non-commercial use only. The Journal of Rheumatology Copyright @ 2014. All rights reserved. 


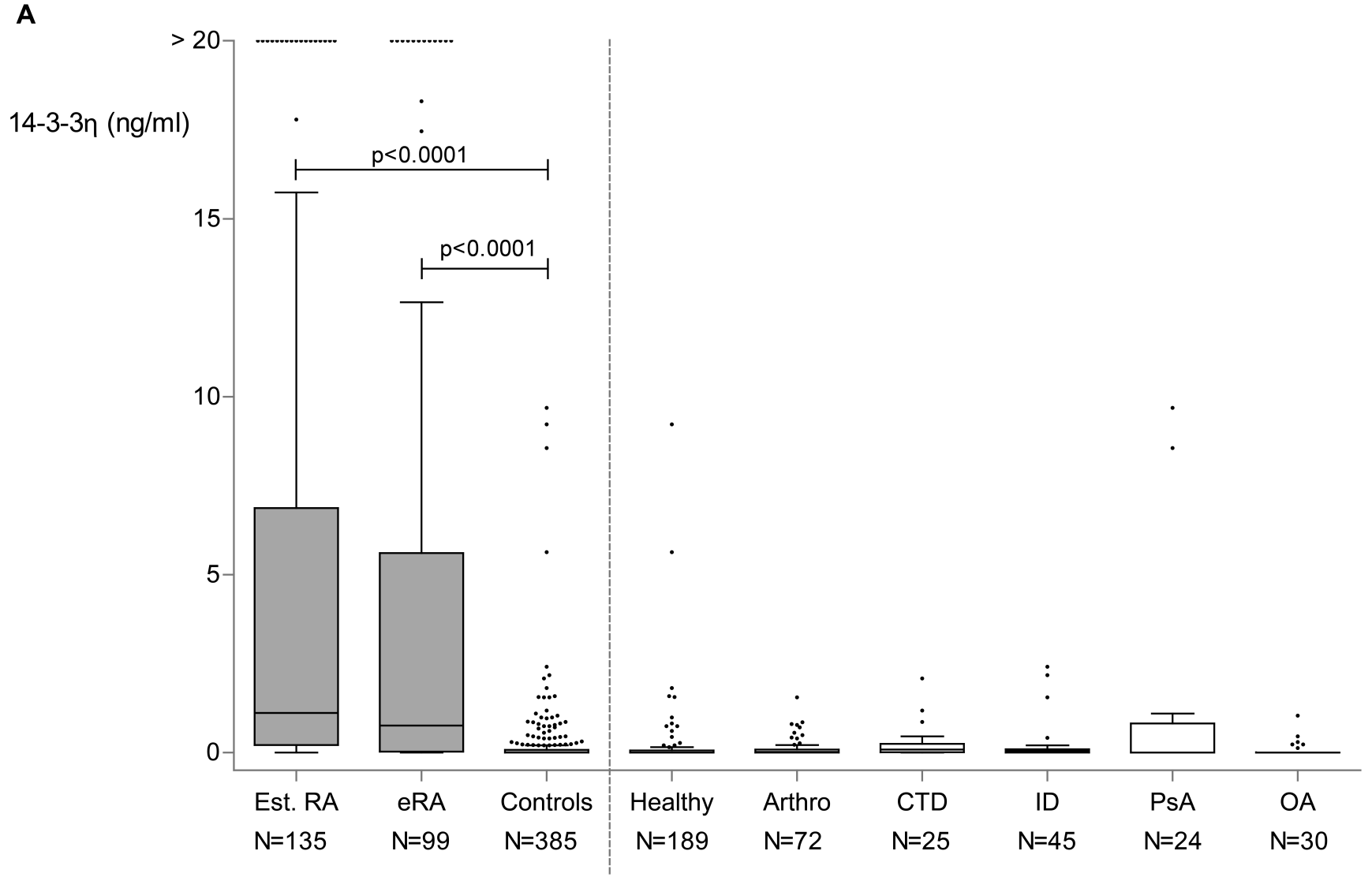

B

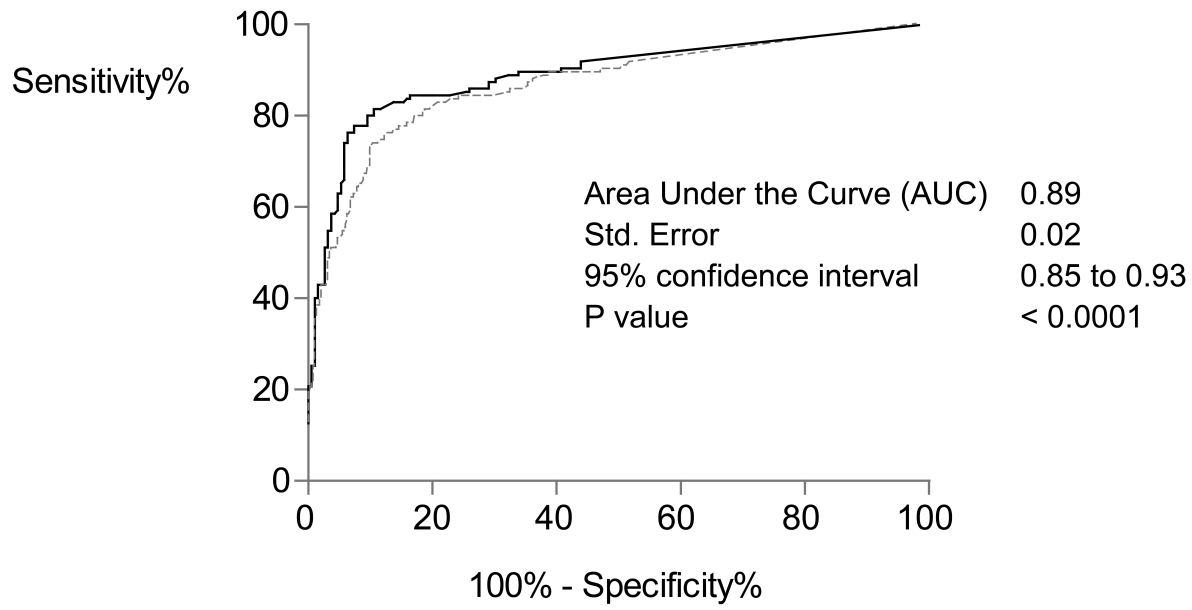

— Est RA vs. Healthy

Est RA vs. All Controls

\section{Sensitivity\% \\ 77.0}

$95 \% \mathrm{CI}$

$69.0 \%$ to $83.8 \%$

\section{Specificity\% \\ 92.6}

$95 \% \mathrm{Cl}$

$87.9 \%$ to $95.9 \%$
Likelihood ratio

10.4

Figure 1. A. Serum 14-3-3ך expression in established and early rheumatoid arthritis (RA) versus controls. B. Corresponding receiver-operating characteristic curve for established RA versus controls.

Personal non-commercial use only. The Journal of Rheumatology Copyright (C) 2014. All rights reserved. 
C

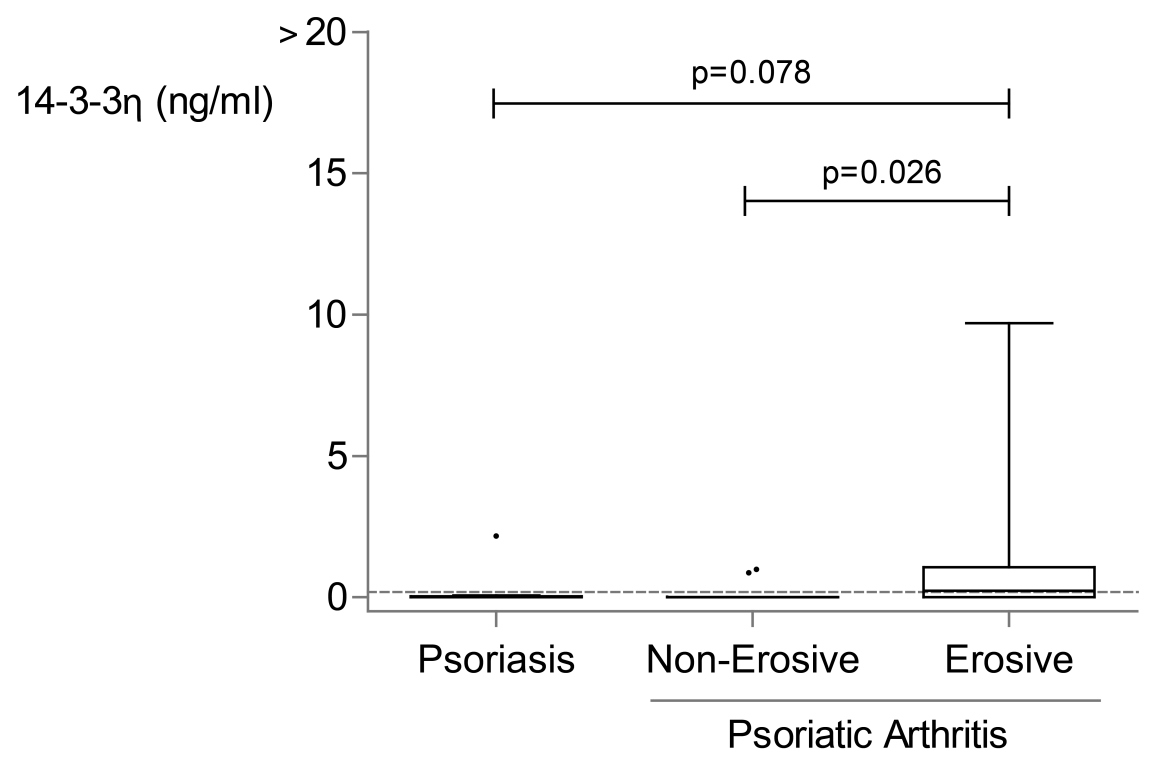

$\begin{array}{llcc}\text { Number of values } & 10 & 12 & 12 \\ \text { Minimum } & 0.0 & 0.0 & 0.0 \\ \text { 25\% Percentile } & 0.0 & 0.0 & 0.0 \\ \text { Median } & 0.0 & 0.0 & 0.23 \\ 75 \% \text { Percentile } & 0.03 & 0.0 & 1.07 \\ \text { Maximum } & 2.17 & 0.99 & 9.69\end{array}$

D

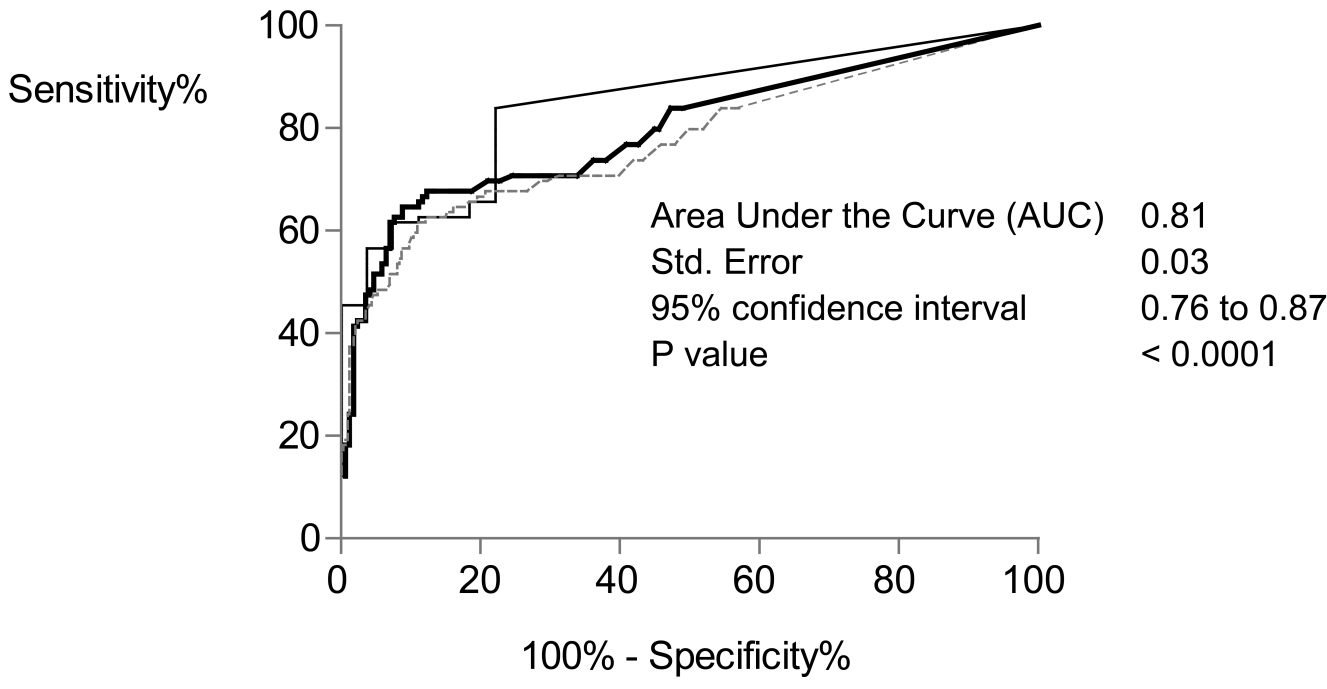

— eRA vs. Healthy

eRA vs OA

eRA vs. All Controls

Sensitivity\%

$>0.19$

63.6
$95 \% \mathrm{Cl}$

$53.4 \%$ to $73.1 \%$
Specificity\%

92.6
$95 \% \mathrm{Cl}$

$87.9 \%$ to $95.9 \%$
Likelihood ratio

8.6

Figure 1.C. Expression in psoriasis and psoriatic arthritis. D. Corresponding receiver-operating characteristic curve for early RA versus controls. eRA: early RA; CTD: connective tissue disorders; ID: inflammatory diseases; PsA: psoriatic arthritis; OA: osteoarthritis. 


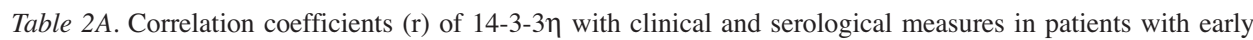
RA. Correlation between HAQ and DAS28 established with a Pearson product-moment correlation because both variables were normally distributed; all other correlations done using Spearman's rank correlation.

\begin{tabular}{lccccccc}
\hline Variable & DAS28 & HAQ & ESR & CRP & RF & ACPA & $14-3-3 \eta$ \\
$\mathrm{N}$ & 99 & 36 & 98 & 97 & 74 & 98 & 99 \\
\hline DAS28 & & & & & & & \\
HAQ & $0.51^{* *}$ & & & & & & \\
ESR & $0.55^{* * * *}$ & 0.33 & & & & \\
CRP & $0.31^{* *}$ & $0.39^{*}$ & $0.62^{* * * *}$ & & & \\
RF & -0.05 & 0.10 & 0.11 & 0.06 & & \\
ACPA & -0.16 & -0.15 & 0.11 & 0.17 & $0.49^{* * * *}$ & & \\
$14-3-3 \eta$ & 0.01 & 0.08 & 0.15 & 0.15 & $0.72^{* * * *}$ & $0.47^{* * * *}$ & \\
\hline
\end{tabular}

${ }^{*} \mathrm{p}<0.05 .{ }^{* *} \mathrm{p}<0.01 . * * * \mathrm{p}<0.001 . * * * \mathrm{p}<0.0001$. RA: rheumatoid arthritis; HAQ: Health Assessment Questionnaire; DAS28: Disease Activity Score; ESR: erythrocyte sedimentation rate; CRP: C-reactive protein; RF: rheumatoid factor; ACPA: anticitrullinated protein antibodies.

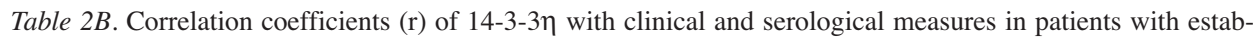
lished RA. Correlation between HAQ and DAS28 established with a Pearson product-moment correlation because both variables were normally distributed; all other correlations Spearman's rank correlation.

\begin{tabular}{lccccccc}
\hline Variable & DAS28 & HAQ & ESR & CRP & RF & ACPA & $14-3-3 \eta$ \\
$\mathrm{N}$ & 75 & 75 & 75 & 74 & 124 & 124 & 135 \\
\hline DAS28 & & & & & & & \\
HAQ & $0.60^{* * * * *}$ & & & & & & \\
ESR & $0.54^{* * * *}$ & $0.31^{* *}$ & & & & & \\
CRP & $0.47^{* * * *}$ & $0.43^{* * *}$ & $0.60^{* * * *}$ & & & \\
RF & 0.23 & 0.17 & 0.13 & 0.06 & & \\
ACPA & 0.16 & 0.21 & 0.07 & 0.21 & $0.51^{* * * *}$ & \\
$14-3-3 \eta$ & 0.09 & 0.12 & 0.19 & 0.08 & $0.60^{* * * *}$ & $0.38^{* * * *}$ & \\
\hline
\end{tabular}

$* * \mathrm{p}<0.01 . * * * \mathrm{p}<0.001 . * * * * \mathrm{p}<0.0001$. RA: rheumatoid arthritis; HAQ: Health Assessment Questionnaire; DAS28: Disease Activity Score, 28-joint count; ESR: erythrocyte sedimentation rate; CRP: C-reactive protein; RF: rheumatoid factor; ACPA: anticitrullinated protein antibodies.

addition of $14-3-3 \eta$ led to notable increases in sensitivity with generally smaller losses in specificity. When comparing the addition of either $14-3-3 \eta$ or RF to ACPA, there were similar increases in sensitivity, but the resulting specificity

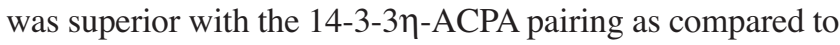
the RF-ACPA pairing (i.e., in the early RA vs healthy cohorts, the RF-ACPA sensitivity/specificity was $0.71 / 0.84$,

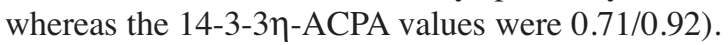

Baseline 14-3-3 $\eta$ positivity and disease severity. The results presented in Table 4 demonstrate that 14-3-3n-positive patients with RA had more severe disease with significantly higher median baseline Disease Activity Score (6.3 vs 5.7, $\mathrm{p}=0.026$ ) and Health Assessment Questionnaire measures (1.9 vs $1.0, \mathrm{p}=0.001$ ) compared to the $14-3-3 \eta$-negative

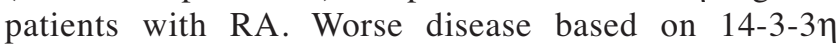
positivity is further corroborated by the significantly higher levels in acute-phase reactants (erythrocyte sedimentation rate, C-reactive protein) and serological measures (RF, ACPA) in the patient group positive for $14-3-3 \eta$ (Table 3 and Figure 2).

\section{DISCUSSION}

Our data showed that 14-3-3 $\eta$ discriminated between patients with early RA and other autoimmune disorders, patients with OA, and healthy controls. This discriminatory capacity was comparable to the established biomarkers RF and ACPA. Serum 14-3-3 $\eta$ assessment enhanced the detection of RA over either RF or ACPA alone by $32 \%$ and $22 \%$, respectively, in patients with early RA. Because there is no correlation with established clinical variables of

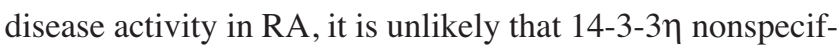
ically reflects inflammation. Rather, our data suggest that it may reflect a more severe phenotype of disease. Our data support the case for incorporating serological markers such as $14-3-3 \eta$ into the framework of the $2010 \mathrm{ACR} /$ European League Against Rheumatism classification criteria for use in diagnosing RA.

Correlation analysis demonstrated minimal associations of $14-3-3 \eta$ with other clinical or laboratory variables, suggesting that $14-3-3 \eta$ provides independent information toward the diagnosis of RA. Results should be regarded as

Personal non-commercial use only. The Journal of Rheumatology Copyright @ 2014. All rights reserved. 


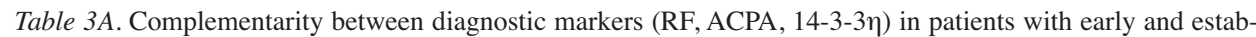
lished RA. Data in parentheses and incremental benefits are in percentages. Serum level of $\geq 0.19 \mathrm{ng} / \mathrm{ml}$ is defined as positive for $14-3-3 \eta$.

\begin{tabular}{|c|c|c|c|c|}
\hline $\begin{array}{l}\text { Diagnostic } \\
\text { Markers }\end{array}$ & $\begin{array}{c}\text { Early RA, } \\
n=99\end{array}$ & $\begin{array}{c}\text { Incremental } \\
\text { Benefit }\end{array}$ & $\begin{array}{l}\text { Established RA, } \\
\qquad \mathrm{n}=124\end{array}$ & $\begin{array}{c}\text { Incremental } \\
\text { Benefit }\end{array}$ \\
\hline $\mathrm{ACPA}+$ & $58(59)$ & - & $98(79)$ & - \\
\hline $\mathrm{RF}+$ & $56(57)$ & - & $105(85)$ & - \\
\hline $14-3-3 \eta+$ & $63(64)$ & - & $95(77)$ & - \\
\hline ACPA and/or RF+ & $71(72)$ & 22 & $109(88)$ & 11 \\
\hline RF and/or $14-3-3 \eta+$ & $74(75)$ & 32 & $117(94)$ & 11 \\
\hline $\mathrm{ACPA}$ and/or $14-3-3 \eta+$ & $71(72)$ & 22 & $119(96)$ & 22 \\
\hline \multicolumn{5}{|l|}{ ACPA and/or RF and/or } \\
\hline $14-3-3 \eta+$ & $77(78)$ & 8 & $119(96)$ & 9 \\
\hline
\end{tabular}

RF: rheumatoid factor; ACPA: anticitrullinated protein antibodies; RA: rheumatoid arthritis.

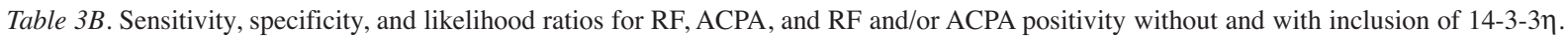

\begin{tabular}{|c|c|c|c|c|}
\hline & $\mathrm{Sn} / \mathrm{Sp}$ & LR+/LR- & $\mathrm{Sn} / \mathrm{Sp}$ & $\mathrm{LR}+/ \mathrm{LR}-$ \\
\hline \multicolumn{5}{|c|}{ Early RA vs healthy controls } \\
\hline $\mathrm{CCP}$ & $0.59 / 0.99$ & $59.00 / 0.41$ & $0.71 / 0.92$ & $8.88 / 0.32$ \\
\hline $\mathrm{RF}$ and/or ACPA & $0.71 / 0.84$ & $4.44 / 0.35$ & $0.78 / 0.78$ & $3.55 / 0.28$ \\
\hline \multicolumn{5}{|c|}{ Early RA vs all controls } \\
\hline $\mathrm{RF}$ and/or ACPA & $0.71 / 0.83$ & $4.18 / 0.35$ & $0.78 / 0.74$ & $3.00 / 0.30$ \\
\hline \multicolumn{5}{|c|}{ Established RA vs healthy controls } \\
\hline $\mathrm{RF}$ & $0.84 / 0.85$ & $5.6 / 0.19$ & $0.88 / 0.79$ & $4.19 / 0.15$ \\
\hline $\mathrm{CCP}$ & $0.79 / 0.99$ & $79.00 / 0.21$ & $0.89 / 0.92$ & $11.13 / 0.12$ \\
\hline $\mathrm{RF}$ and/or ACPA & $0.88 / 0.84$ & $5.5 / 0.14$ & $0.90 / 0.78$ & $4.09 / 0.13$ \\
\hline \multicolumn{5}{|c|}{ Established RA vs all controls } \\
\hline
\end{tabular}

RF: rheumatoid factor; ACPA: anticitrullinated protein antibodies; Sn: sensitivity; Sp: specificity; LR+: positive likelihood ratio; LR-: negative likelihood ratio; RA: rheumatoid arthritis; CCP: cyclic citrullinated peptide.

preliminary in view of the limited sample size in the cohort with early RA and the selection of patients for high disease activity in the cohort with established RA. Nevertheless, this biomarker is modifiable and there are data that serum levels as well as the short-term change in serum levels are associated with clinical response to anti-TNF- $\alpha$ agents ${ }^{15}$.

The role of ACPA in the diagnosis of RA is now well established, largely based on prospective data indicating that it has a PPV of about $95 \%$ for the development of RA in populations of patients with undifferentiated arthritis, though its NPV is only about $60-70 \% 16,17$. Our data describe the first analysis of the $14-3-3 \eta$ biomarker in cross-sectional cohorts, which is an essential first step in the investigation of a biomarker's diagnostic utility. Further analyses are now warranted in unselected cohorts with undifferentiated arthritis who have been followed prospectively to determine which patients develop RA. ACPA is also of clinical value because it has been shown to possess predictive capacity for radiographic progression in $\mathrm{RA}^{1,18}$. However, studies in early RA have shown that the contribution of ACPA together with other predictive clinical variables contributes only about $32 \%$ of the total risk for radiographic progression ${ }^{9}$. Because cross-sectional data suggest that 14-3-3 $\eta$ may be independently associated with radiographic damage in both $\mathrm{RA}$ and $\mathrm{Ps}^{19}$, and because it has been shown to upregulate expression of MMP and RANKL, a prospective study is also warranted to examine its capacity as an independent predictor of radiographic progression.

We previously reported that $14-3-3 \eta$ concentrations are 5 -fold higher in synovial fluid than in matched serum ${ }^{10}$. In vitro data show that the soluble extracellular form of 14-3-3 $\eta$ activates several proinflammatory signaling cascades relevant to $\mathrm{RA}^{13}$. A notable exception contrasting 


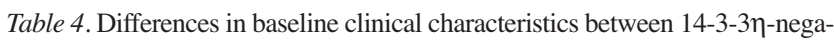
tive and -positive patients with RA (combined cohorts). Except for $\mathrm{p}$ values, all data are median (IQR).

\begin{tabular}{lccc}
\hline & $\begin{array}{c}14-3-3 \eta \text { Negative, } \\
\mathrm{n}=67\end{array}$ & $\begin{array}{c}14-3-3 \eta \text { Positive, } \\
\mathrm{n}=167\end{array}$ & $\mathrm{p}$ \\
\hline & $55(48-66)^{67}$ & $58(47-66)^{167}$ & 0.76 \\
Age, yrs & $5.7(4.6-6.4)^{44}$ & $6.3(5.2-7.2)^{130}$ & 0.026 \\
DAS & $1.0(0.8-1.8)^{20}$ & $1.9(1.4-2.4)^{91}$ & 0.001 \\
HAQ & $25(14-35)^{43}$ & $38(20-48)^{130}$ & 0.003 \\
ESR, mm/h & $9.0(3.0-26.8)^{43}$ & $19.2(8.0-47.4)^{128}$ & 0.006 \\
CRP, mg/l & $11.4(10.0-40.0)^{54}$ & $43.5(10.0-154.8)^{146}$ & 0.004 \\
RF, IU/ml & $5.0(2.0-20.0)^{36}$ & $489.0(48.5-1279)^{62}$ & 0.0001 \\
ACPA, U/ml & & & \\
\hline
\end{tabular}

Superscripted numbers refer to the number of patients within the group. RA: rheumatoid arthritis; IQR: interquartile range; DAS: Disease Activity Score; HAQ: Health Assessment Questionnaire; ESR: erythrocyte sedimentation rate; CRP: C-reactive protein; RF: rheumatoid factor; ACPA: anticitrullinated protein antibodies.

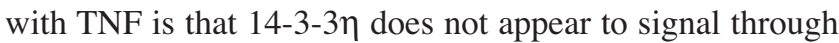
the $\mathrm{p} 38 \mathrm{MAP}$ kinase and nuclear factor- $\kappa \mathrm{B}$ pathways. Serum 14-3-3 $\eta$ has also been described as a potent inducer of MMP in vitro, and levels of $14-3-3 \eta$ correlate with MMP expression in serum and synovial fluid of patients with RA, suggesting that it may play a role in the joint damage cascade $^{10,13}$. We have also reported data suggesting an association between serum 14-3-3 $\eta$ levels and radiographic damage in patients with PsA, also described herein. However, 14-3-3 $\eta$ levels are lower in PsA compared to RA, and detectable only in those patients with erosive PsA.
Serum 14-3-3 $\eta$ is a constituent of exosomes, and following extracellular release has been shown to participate in a positive feedback interactive loop with TNF in promoting

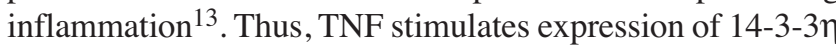
while $14-3-3 \eta$ stimulates expression of TNF, and this may be relevant to the finding that $14-3-3 \eta$ is elevated in both patients with RA and patients with PsA with more severe radiographic changes.

The 14-3-3 $\eta$ ELISA assay has undergone substantial preclinical validation, exhibiting strong analytical performance as determined by high sensitivity, assay precision of $9 \%$, lack of significant cross-reactivity with other isoforms, absence of affect by potential interfering substances such as RF and various therapeutics used in RA (including infliximab), and absence of sample drift over time. The assay has also been validated according to several criteria proposed by the Outcome Measures in Rheumatology Soluble Biomarker Working Group ${ }^{20}$ : it performs similarly in paired serum and plasma samples, the marker demonstrates stability over 3 days at room temperature and $4^{\circ} \mathrm{C}$, and it exhibits limited variability according to age and sex (as described in the supplementary data available online at jrheum.org).

We have shown that $14-3-3 \eta$ is a biomarker that discriminates both early and established RA when compared to healthy and disease controls that include patients with other

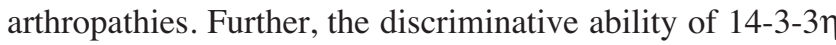
was comparable to RF and ACPA, and enhanced their diagnostic capacity. Our work therefore supports continuing

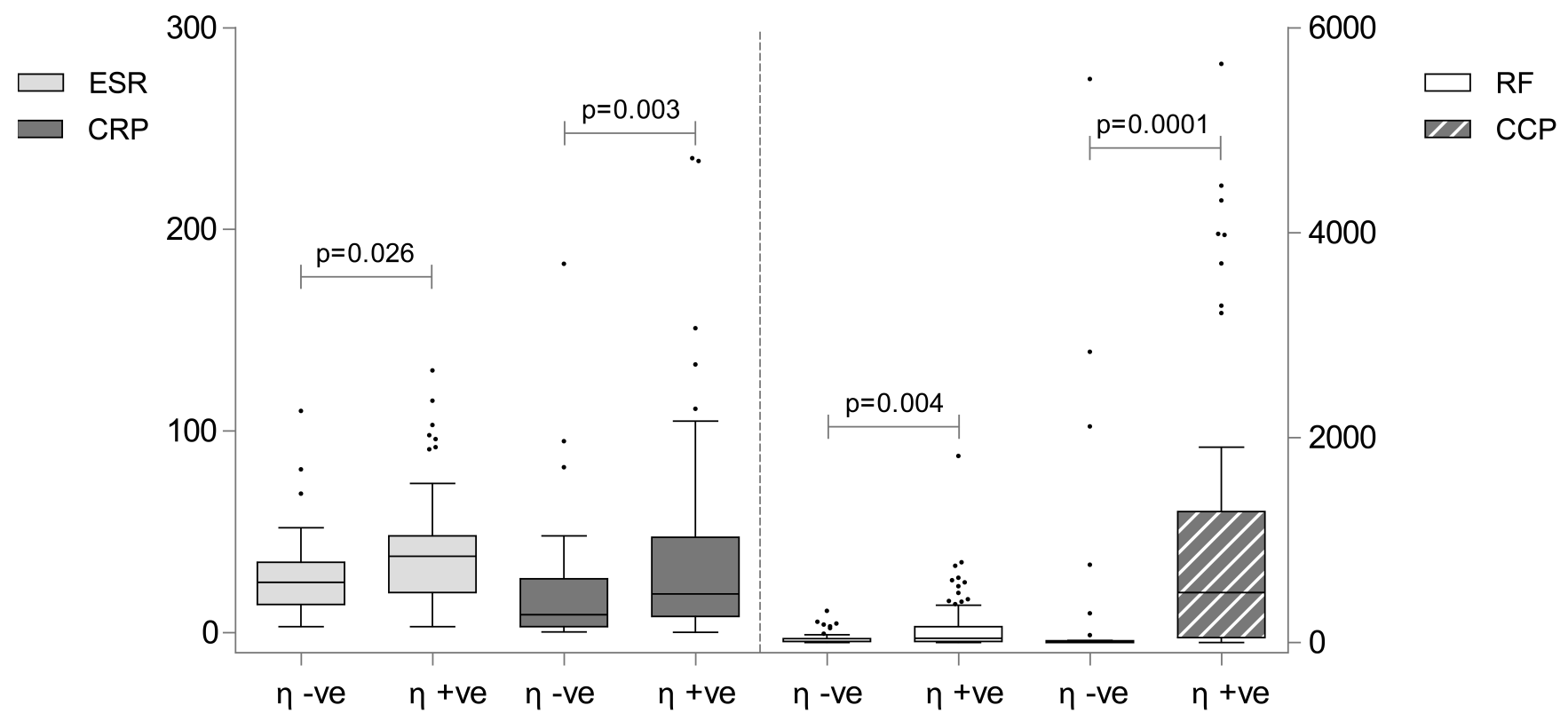

14-3-3n Status

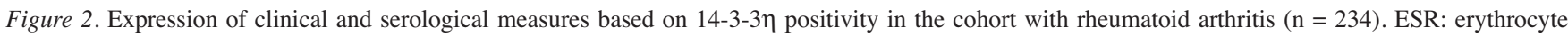
sedimentation rate; CRP: C-reactive protein; RF: rheumatoid factor; CCP: anticyclic citrullinated peptide antibodies. 
evaluation of the diagnostic utility of this biomarker. Through earlier and more accurate diagnosis of RA, patients can be provided earlier access to disease-modifying therapy to preserve joint function and minimize the economic and personal costs of RA.

\section{ACKNOWLEDGMENT}

We thank Dr. Mairead Murphy and Dr. K. Shawn Davison for their assistance in the preparation of this manuscript.

\section{ONLINE SUPPLEMENT}

Supplementary data for this article are available online at jrheum.org.

\section{REFERENCES}

1. Tanikawa C, Ueda K, Nakagawa H, Yoshida N, Nakamura Y, Matsuda K. Regulation of protein Citrullination through p53/PADI4 network in DNA damage response. Cancer Res 2009;69:8761-9.

2. Sokka T. Work disability in early rheumatoid arthritis. Clin Exp Rheumatol 2003;21:S71-4.

3. Verstappen SM, Bijlsma JW, Verkleij H, Buskens E, Blaauw AA, ter Borg EJ, et al. Overview of work disability in rheumatoid arthritis patients as observed in cross-sectional and longitudinal surveys. Arthritis Rheum 2004;51:488-97.

4. Young A, Dixey J, Kulinskaya E, Cox N, Davies P, Devlin J, et al. Which patients stop working because of rheumatoid arthritis? Results of five years' follow up in 732 patients from the Early RA Study (ERAS). Ann Rheum Dis 2002;61:335-40.

5. Vermeer M, Kuper HH, Hoekstra M, Haagsma CJ, Posthumus MD, Brus HL, et al. Implementation of a treat-to-target strategy in very early rheumatoid arthritis: results of the Dutch Rheumatoid Arthritis Monitoring remission induction cohort study. Arthritis Rheum 2011;63:2865-72.

6. Aletaha D, Neogi T, Silman AJ, Funovits J, Felson DT, Bingham CO III, et al. 2010 rheumatoid arthritis classification criteria: an American College of Rheumatology/European League Against Rheumatism collaborative initiative. Arthritis Rheum 2010;62:2569-81.

7. Burr ML, Viatte S, Bukhari M, Plant D, Symmons DP, Thomson W, et al. Long-term stability of anti-cyclic citrullinated peptide antibody status in patients with early inflammatory polyarthritis. Arthritis Res Ther 2012;14:R109.

8. Mjaavatten MD, van der Heijde DM, Uhlig T, Haugen AJ, Nygaard $\mathrm{H}$, Bjørneboe O, et al. Should anti-citrullinated protein antibody and rheumatoid factor status be reassessed during the first year of followup in recent-onset arthritis? A longitudinal study. J Rheumatol 2011;38:2336-41.
9. de Rooy DP, van der Linden MP, Knevel R, Huizinga TW, van der Helm-van Mil AH. Predicting arthritis outcomes - what can be learned from the Leiden Early Arthritis Clinic? Rheumatology 2011;50:93-100.

10. Kilani RT, Maksymowych WP, Aitken A, Boire G, St-Pierre Y, Li $\mathrm{Y}$, et al. Detection of high levels of 2 specific isoforms of 14-3-3 proteins in synovial fluid from patients with joint inflammation. J Rheumatol 2007;34:1650-7.

11. Chavez-Munoz C, Kilani RT, Ghahary A. Profile of exosomes related proteins released by differentiated and undifferentiated human keratinocytes. J Cell Physiol 2009;221:221-31.

12. Thery C, Ostrowski M, Segura E. Membrane vesicles as conveyors of immune responses. Nat Rev Immunol 2009;9:581-93.

13. Maksymowych WP, van der Heijde DM, Allaart CF, Landewé R, Boire G, Tak PP, et al. 14-3-3eta is a novel mediator associated with the pathogenesis of rheumatoid arthritis and joint damage. Arthritis Res Ther 2014;16:R99.

14. Arnett FC, Edworthy SM, Bloch DA, McShane DJ, Fries JF, Cooper NS, et al. The American Rheumatism Association 1987 revised criteria for the classification of rheumatoid arthritis. Arthritis Rheum 1988;31:315-24.

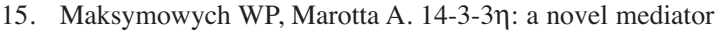
upregulated by TNF $\alpha$, reflects clinical response to anti-TNF $\alpha$ therapy [abstract]. Arthritis Rheum 2011;63 Suppl 10:S162-3.

16. Vander CB, Hoffman IE, Peene I, Union A, Mielants H, Meheus L, et al. Prediction models for rheumatoid arthritis during diagnostic investigation: evaluation of combinations of rheumatoid factor, anti-citrullinated protein/peptide antibodies and the human leucocyte antigen-shared epitope. Ann Rheum Dis 2007;66:364-9.

17. Vander Cruyssen B, Cantaert T, Nogueira L, Clavel C, De Rycke L, Dendoven A, et al. Diagnostic value of anti-human citrullinated fibrinogen ELISA and comparison with four other anti-citrullinated protein assays. Arthritis Res Ther 2006;8:R122.

18. Raza K, Breese M, Nightingale P, Kumar K, Potter T, Carruthers $\mathrm{DM}$, et al. Predictive value of antibodies to cyclic citrullinated peptide in patients with very early inflammatory arthritis. J Rheumatol 2005;32:231-8.

19. Marotta A, van Kuijk AW, Maksymowych WP, Tak PP. Serum

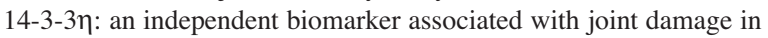
psoriatic arthritis [abstract]. Ann Rheum Dis 2012;71 Suppl 3:S576.

20. Maksymowych WP, Landewe R, Tak PP, Ritchlin CJ, Ostergaard $\mathrm{M}$, Mease PJ, et al. Reappraisal of OMERACT 8 draft validation criteria for a soluble biomarker reflecting structural damage endpoints in rheumatoid arthritis, psoriatic arthritis, and spondyloarthritis: the OMERACT 9 v2 criteria. J Rheumatol 2009;36:1785-91. 